\title{
Acute effects of vinegar intake on some biochemical risk factors of atherosclerosis in hypercholesterolemic rabbits
}

\author{
Mahbubeh Setorki ${ }^{*}$, Sedighe Asgary ${ }^{2}$, Akram Eidi $^{1}$, Ali Haeri rohani ${ }^{1}$, Majid KHazaei $^{3}$
}

\begin{abstract}
Background: Exaggerated postprandial spikes in blood glucose and lipids induce proportional increases in oxidative stress, which acutely trigger impairment endothelial, inflammation and increased risk of future cardiovascular events. In this research, we have investigated acute effects of vinegar intake on some of the biochemical atherosclerosis risk factors in high cholesterol fed rabbits to see if we can find a probable protective value for it.

Methods: The rabbits were randomly divided into four groups: normal diet, high cholesterol diet (\%1cholesterol), $\% 1$ cholesterol with $5 \mathrm{ml}$ vinegar (low dose), \%1 cholesterol with $10 \mathrm{ml}$ vinegar (high dose). After fasting for 12-15 hours, blood samples were taken to determine baseline values. Three hours after feeding, blood samples were collected again to investigate acute effects of vinegar intake on the measured factors.

Results: Using high-dose vinegar with cholesterolemic diet caused significant reduce in LDL-cholesterol (LDL-C), oxidized-LDL (ox-LDL), malondialdehyde (MDA), total cholesterol (TC) and apolipoprotein B (ApoB) in comparison with hypercholesterolemic diet. Consumption low-dose vinegar with cholesterolemic diet induced a significant decrease in fibrinogen and glucose compared to hypercholesterolemic diet. Level of serum nitrite, nitrate, triacylglycerol (TAG), HDL-cholesterol (HDL-C), apolipoprotein A (ApoA), serum glutamic pyruvic transaminase (SGPT), serum glutamic oxaloacetate transaminase (SGOT) and C-reactive protein (CRP) were not significantly difference in low and high doses vinegar with cholesterolemic diet compared to hypercholesterolemic diet. A significant difference was observed for LDL-C, ApoB100 and TC between low and high doses vinegar.
\end{abstract}

Conclusion: This study suggest that vinegar, might have some acute effects on biochemical risk factors of atherosclerosis and a probable protective value can be considered for its postprandial use.

\section{Introduction}

Atherosclerosis, a chronic inflammatory response affecting arterial blood vessels, is the leading cause of death in the developed world. Endothelium has an important role in vascular tone regulation and its dysfunction is a key factor in progression of atherosclerosis. Several studies have shown that a transient increase in blood concentrations of triglycerides (TG) and fatty acids can affect endothelium-dependent vasodilatation [1,2]. Considering that after each meal, blood concentrations of glucose and lipids are raised and this postprandial

\footnotetext{
* Correspondence: doctor.setorgi@gmail.com
'Department of Biology, Science and Research Branch, Islamic Azad

* Correspondence: doctor.setorgi@gmail.com
'Department of Biology, Science and Research Branch, Islamic Azad University, Tehran, Iran
}

(C) 2010 Setorki et al; licensee BioMed Central Ltd. This is an Open Access article distributed under the terms of the Creative Commons

increase lasts for a rather long time, these changes might be of importance in the process of atherosclerosis initiation and progression [3]. It has been also suggested that hypertriglyceridemia and hyperglycemia result in production of reactive oxygen species (ROS) which it leads to the activation of nuclear factor-kappaB [4]. This factor is a transcription factor which is contributed in immunity, inflammation and regulation of cell proliferation, growth and apoptosis by controlling the expression of many genes [5]. These are all among the mechanisms that might be contributed in the progression of atherosclerosis [4]. Patients with higher TG level have had raised concentration of soluble adhesion molecules. Also, postprandial lipoproteins can induce membrane 
expression of adhesion molecules which might be mediated by the oxidative changes of these particles [6].

Atherosclerosis can prevent and treat with different drugs. Because of length of therapy and vast majority side effects of chemical drugs in treatment of atherosclerosis, herbal medication may be suitable substitute for these drugs. Dietary phenolic compounds, in vegetables and fruits and their juices have shown antioxidant activity which can have positive effect on human health [7] so we examined postprandial effects of vinegar intake on biochemical risk factors of atherosclerosis in high cholesterol fed rabbit.

Vinegar is one of the products of grape. A number of studies have demonstrated that grape juice can decrease cholesterol [8] improve endothelial function [9] and enhancing the resistance to oxidative modification of low density lipoprotein (LDL) [9].

Vinegar which is used commonly as a condiment has been proven to have some medical uses as well. Acetic acid is the main component of vinegar. Some other constituents include, anthocyanins (e.g. Cyanidin-3-glucoside) flavonols (e.g. quercetin, kaempferol), flavanols (Catechin, epicatechin) [10], vitamins, mineral salts, amino acids and nonvolatile organic acids (eg. tartaric, citric, malic, lactic) [11]. Vinegar has shown such multiple effects as enhancement of glycogen repletion [12], prevention of hypertension [13], stimulation of $\mathrm{Ca}^{+2}$ absorption [14] and reduction serum total cholesterol and triacylglycerol in animal studies [15]. Many recent studies have documented that vinegar ingestion decreases the glucose response to a carbohydrate load in normal and diabetic subjects [16,17]. All these data suggests a probable protective value for vinegar. Considering that vinegar is a safe product, widely available and affordable, we studied acute effects of vinegar intake on some of the most important risk factors of atherosclerosis in rabbits fed a high cholesterol diet.

\section{Experimental methods}

\section{Preparation of the plant}

First the genus and species were verified by a botanist (Vitis Sylvestris, herbarium number 15810) from the Research Center of Isfahan Province Natural Resources. Then the grapes were collected in Aminabad region of Isfahan and vinegar was produced with traditional methods [18]. In order to standardize the vinegar, some factors such as density, $\mathrm{pH}$, vitamin $\mathrm{C}$, acetic acid, anthocyanin and flavonoids were measured.

\section{Animals and experimental design}

Thirty two male New Zealand rabbits with an average body weight of $1910 \pm 257$ g were procured from Razi Institute of Iran. The animals were acclimatized under room temperature and humidity with regular light/dark cycle for two weeks and had free access to water and a standard powdered purified diet (Dampars Co, Iran) which consisted of $10 \%$ protein, $40-50 \%$ carbohydrates, $2 \%$ vegetable fat and $15-25 \%$ fiber. At the end of this period, rabbits were randomly divided into four groups of eight. Animals were fasted for 12-15 hours and venous blood samples were taken to determine baseline values. After this, each group received one of the four experimental diets: normal diet, high cholesterol diet (\% 1cholesterol), \%1 cholesterol with $5 \mathrm{ml}$ vinegar (low dose), and \% 1 cholesterol with $10 \mathrm{ml}$ vinegar (high dose). The cholesterol (1 g for each animal) was dissolved in $2 \mathrm{ml}$ olive oil given to high cholesterol diet animals by oral gavage once. The same volume of olive oil was given to control animals. After cholesterol gavage, the vinegar ( 5 or $10 \mathrm{ml}$ )was also given orally to animals by oral gavage $[19,20]$. After 3 hours of the first dose of experimental diets (this period falls within the steady-state period of lipid absorption), again venous blood samples were collected in order to study the acute effects of vinegar [21]. The study was reviewed and approved by the ethics committee of Isfahan University of medical sciences.

\section{Measurement biochemical factors in rabbit}

Blood samples were centrifuged at $3500 \mathrm{rpm}$ for 20 minutes to obtain serum and plasma. The plasma was used for fibrinogen and malondialdehyde (MDA) measurement and the serum for other biomarkers.

Serum total cholesterol (TC), triacylglycerol (TAG), low density lipoprotein cholesterol (LDL-C), high density lipoprotein cholesterl (HDL-C), apolipoprotein A (ApoA), apolipoprotein B (ApoB), serum glutamic pyruvic transaminase (SGPT), glucose, oxaloaetate transaminase (SGOT) and serum glucose were determined using standard enzymatic kits (Pars Azmoon Co, Iran) and auto analyzer (Hitachi 902, Japan). MDA was measured by spectrophotometric method [22]. Oxidized LDL (oxLDL) (Promokine Co, Germany), C- reactive protein (CRP) (Kamiya Biomedical Co, CRP ELISA Rabbit, USA) were measured using enzyme-linked immunosorbent assay kit according to manufacturer's instructions and fibrinogen was measured using coagulation kit (Mahsayaran Co, Iran). The serum level of nitrite and nitrate were measured using a colorimetric assay kit (R\&D Systems, USA) that involves the Griess reaction.

\section{Measurement physiochemical factors in vinegar}

$\mathrm{pH}$ was determined by $\mathrm{pH}$ meter, density by densitometer, vitamin $\mathrm{C}$ assayed by spectrophotometeric method at $520 \mathrm{~nm}$ and determined photometrically with 2,4 dinitrophenyl hydrazine to form the red bis-hydrazone which is reduced to a coloreless form [23], total flavonoid content was measured by aluminum chloride 
colorimetric assay. The absorbance was measured against prepared reagent blank at $510 \mathrm{~nm}$ [24], total anthocyanin was assayed by spectrophotometeric method at535 nm [25] and the method used to measure the total acidity of the vinegar is an analytical chemistry technique called an acid-base titration [26].

\section{Statistical analysis}

Results are given as Mean \pm SD. Data were analyzed statistically using One-Way-ANOVA test followed by LSD post test. Differences between the baseline values and the values postprandial calculated and then used OneWay-ANOVA for comparing between groups. Then pairwise multiple comparisons were performed using LSD post test. In all instances, $\mathrm{p}$ value less than 0.05 was considered significant.

\section{Results}

Determination of some physiochemical factors in vinegar After analyzing vinegar factors the amount of vitamin $\mathrm{C}$ was $8.02 \pm 0.02(\mathrm{mg} / \mathrm{dl})$, acetic acid percent $15.81 \% \pm 0.04$, total anthocyanin in $100 \mathrm{~g}$ of vinegar $3.25 \pm 1.02(\mathrm{mg} / 100$ g) and flavonoids in $100 \mathrm{ml}$ of vinegar $1.071 \pm 0.06(\mathrm{~g} / 100$ $\mathrm{ml}$ equivalent naringenin). The density and $\mathrm{pH}$ were 1.042 $\pm 0.002\left(\mathrm{~g} / \mathrm{cm}^{3}\right)$ and $3.58 \pm 0.01$ respectively.

\section{Glucose, lipoprotein and apolipoprotein}

In high-cholesterol group, serum glucose levels was increased significantly compared to the normal-diet group $(P<.0001)$. Using low-dose vinegar with cholesterolemic diet induced a significant decrease in serum glucose compared to hypercholesterolemic diet $(P=.007)$, but the difference was not significant after high-dose vinegar. No significant difference was found between two control groups with regard to TC, TAG, LDL-C, HDL-C, and ApoA1 and ApoB100. Following concurrent use of high-dose vinegar with cholesterolemic diet, ApoB100, TC and LDL-C levels were significantly decreased in comparison with hypercholesterolemic diet $\operatorname{group}(P=$ $.049 P=.007, P=.027$ respectively). Consumption of low-dose vinegar with cholesterolemic diet did not change serum lipoproteins and apolipoproteins levels significantly in comparison with hypercholesterolemic diet. Similar results were observed for TG, ApoA1 and HDL$\mathrm{C}$ when compared between high cholesterol diet group and high-dose vinegar with cholesterolemic diet group. Significant differences were observed between low and high-dose vinegar groups by TC, LDL-C, ApoB100 ( $P=$ $.013, P=.025, P=.038$ respectively). ApoA1 concentration was increased in low-dose vinegar with cholesterolemic diet group compared to rabbits fed high cholesterolemic diet, but the difference was not significant $(P=.057)($ Table 1$)$.

\section{Serum transaminases levels}

No significant difference in serum SGOT and SGPT levels were found between low- and high-dose vinegar with cholesterolemic diet groups compared to hypercholesterolemic diet group $(P>.05)$ (Table 2).

\section{Endothelial markers}

The serum level of nitrite in normal diet control was significantly decreased comparison with hypercholesterolemic diet $(P=.01)$. Nitrite concentration was

Table 1 Comparison of glucose, lipoproteins and apolipoproteins values before (baseline) and after (postprandial) experimental diet

\begin{tabular}{|c|c|c|c|c|c|}
\hline \multirow[t]{2}{*}{ Biochemical factors(mg/dl) } & & \multicolumn{4}{|l|}{ Groups } \\
\hline & & Cholesterolemic diet & $5 \mathrm{ml}$ Vinegar with $\% 1 \mathrm{chol}$ & $10 \mathrm{ml}$ Vinegar with $\% 1 \mathrm{chol}$ & Normal diet \\
\hline \multirow[t]{2}{*}{ glucose } & baseline & $64.8 \pm 17.4$ & $87.5 \pm 20.9$ & $80.2 \pm 13.2$ & $91.75 \pm 5.7$ \\
\hline & postprandial & $122.8 \pm 16.4$ & $102.6 \pm 22.1^{*}$ & $124.8 \pm 19.8$ & $92.65 \pm 7.9^{*}$ \\
\hline \multirow[t]{2}{*}{ TC } & baseline & $61.8 \pm 12.1$ & $71.2 \pm 15.7$ & $96.2 \pm 33.8$ & $97.8 \pm 23.7$ \\
\hline & postprandial & $92.8 \pm 40.4$ & $95 \pm 31.3 \#$ & $51 \pm 7.7^{*}$ & $89.5 \pm 19.4$ \\
\hline \multirow[t]{2}{*}{ LDL-C } & baseline & $32.5 \pm 12.2$ & $38.7 \pm 12.4$ & $57 \pm 26.5$ & $49.3 \pm 22.5$ \\
\hline & postprandial & $44.8 \pm 30.5$ & $49 \pm 24.9 \#$ & $22.5 \pm 4^{*}$ & $44.8 \pm 18$ \\
\hline \multirow[t]{2}{*}{$\mathrm{HDL}-\mathrm{C}$} & baseline & $16.7 \pm 3$ & $20 \pm 6.2$ & $23.7 \pm 9.4$ & $25.3 \pm 4.5$ \\
\hline & postprandial & $14.33 \pm 4.08$ & $19.8 \pm 2.3$ & $15.8 \pm 5.3$ & $19.5 \pm 4.2$ \\
\hline \multirow[t]{2}{*}{ TAG } & baseline & $148.7 \pm 62.9$ & $166.7 \pm 40.4$ & $166.5 \pm 73.2$ & $149.5 \pm 56.2$ \\
\hline & postprandial & $164 \pm 54.6$ & $167 \pm 70.1$ & $148 \pm 44.7$ & $166.3 \pm 61.1$ \\
\hline \multirow[t]{2}{*}{ ApoA1 } & baseline & $20.8 \pm 2.5$ & $22.2 \pm 4.8$ & $24.5 \pm 4.7$ & $34 \pm 2.4$ \\
\hline & postprandial & $19.08 \pm 2.42$ & $26.6 \pm 3.4$ & $21.8 \pm 5.6$ & $29.5 \pm 3.5$ \\
\hline \multirow[t]{2}{*}{ ApoB100 } & baseline & $5.2 \pm 2.5$ & $7.7 \pm 3.4$ & $8.2 \pm 2.6$ & $4.5 \pm 1.9$ \\
\hline & postprandial & $5.8 \pm 3$ & $8.4 \pm 4.83 \#$ & $3.55 \pm 1^{*}$ & $4.3 \pm 2.1$ \\
\hline
\end{tabular}

Mean serum glucose, TC, LDL-C, HDL-C, TAG, ApoA1, ApoB100, mg/dl \pm SD, in each group ( $\mathrm{n}=8$ for each experimental group).* $<$ < 0.05 : Pairwise comparison of differences between baseline and postprandial when compared to cholesterolemic group. \# $\mathrm{p}<0.05$, Mean differences between baseline and postprandial $5 \mathrm{ml}$ vinegar with respect to $10 \mathrm{ml}$ vinegar. 
Table 2 Comparison of serum glutamic pyruvic transaminase(SGPT), serum glutamic oxaloacetate transaminase(SGOT) before (baseline) and after (postprandial) experimental diet

\begin{tabular}{|c|c|c|c|c|c|}
\hline Biochemical factors $(\mathrm{u} / \mathrm{l})$ & & Groups & & & \\
\hline & & Cholesterolemic diet & $5 \mathrm{ml}$ Vinegar with $\% 1 \mathrm{chol}$ & $10 \mathrm{ml}$ Vinegar with $\% 1 \mathrm{chol}$ & Normal diet \\
\hline \multirow[t]{2}{*}{ SGOT } & baseline & $62.7 \pm 19.7$ & $71.8 \pm 36.8$ & $57.5 \pm 48.3$ & $56.25 \pm 14.7$ \\
\hline & postprandial & $80.4 \pm 20.6$ & $61.4 \pm 26.1$ & $72.5 \pm 23.8$ & $41.5 \pm 23.4$ \\
\hline \multirow[t]{2}{*}{ SGPT } & baseline & $62.8 \pm 16.5$ & $70 \pm 21.2$ & $58.2 \pm 43.1$ & $50.25 \pm 4.1$ \\
\hline & postprandial & $74 \pm 18.2$ & $70.6 \pm 18.6$ & $75.5 \pm 30.7$ & $37.3 \pm 13$ \\
\hline
\end{tabular}

Mean SGOT and SGPT, $\mathrm{u} / \mathrm{I} \pm \mathrm{SD}$, in each group ( $\mathrm{n}=8$ for each experimental group).

Table 3 Comparison of nitrite and nitrate values before (baseline) and after (postprandial) experimental diet

\begin{tabular}{|c|c|c|c|c|c|}
\hline \multirow[t]{2}{*}{ Biochemical factors $(\mu \mathrm{mol} / \mathrm{l})$} & & \multicolumn{4}{|l|}{ Groups } \\
\hline & & Cholesterolemic diet & $5 \mathrm{ml}$ Vinegar with $\% 1 \mathrm{chol}$ & $10 \mathrm{ml}$ Vinegar with $\% 1 \mathrm{chol}$ & Normal diet \\
\hline \multirow[t]{2}{*}{ Nitrite } & baseline & $33.78 \pm 23.1$ & $31.19 \pm 18.4$ & $32.54 \pm 32.7$ & $34.49 \pm 21.0$ \\
\hline & postprandial & $81.17 \pm 28.8$ & $58.27 \pm 28.2$ & $62.62 \pm 42.0$ & $20.32 \pm 3.6^{*}$ \\
\hline \multirow[t]{2}{*}{ Nitrate } & baseline & $17.9 \pm 5.1$ & $19.7 \pm 6.9$ & $17.0 \pm 2.1$ & $16.7 \pm 1.6$ \\
\hline & postprandial & $23.0 \pm 8.6$ & $24.1 \pm 5.1$ & $20.4 \pm 8.7$ & $12.3 \pm 3.5$ \\
\hline
\end{tabular}

Mean Nitrite and Nitrate, $\mu \mathrm{mol} / \mathrm{I} \pm \mathrm{SD}$, in each group $(\mathrm{n}=8$ for each experimental group).* $\mathrm{p}<0.05$ : Pairwise comparison of differences between baseline and postprandial when compared to cholesterolemic group.

decreased in low-and high-dose vinegar with hypercholesterolemic diet groups compared to rabbits fed high cholesterolemic diet, but the difference was not signifi$\operatorname{cant}(P>.05)$. No significant difference in nitrate concentration was found between low and high-dose vinegar with cholesterolemic diet groups compared to hypercholesterolemic diet group (Table 3).

\section{Inflammatory factors}

High cholesterol control induced a significantly increase in fibrinogen comparison with low-dose vinegar with cholesterolemic diet $(P=.01)$. Though reduced fibrinogen level was found in high-dose vinegar with cholesterolemic diet comparison to hypercholesterolemic diet but the difference was not significant.

In high cholesterol group, CRP was increased significantly compared to the normal diet group $(P<.0001)$. No significant difference was found between low and high-doses vinegar with cholesterolemic diet compared to hypercholesterolemic diet. Also, no significant difference was shown between low and high-doses of vinegar (Table 4).

\section{Oxidative factors}

MDA increased significantly in hypercholesterolemic diet comparison with normal control diet $(P=.001)$. Consumption of high-dose vinegar with cholesterolemic diet induced a significantly decrease in MDA comparison with hypercholesterolemic diet $(P=.031)$. No difference significant between low and high doses of vinegar.

Significant difference was observed between hypercholesterolemic diet compared to normal diet by ox-LDL ( $P$ $=.035)$. Using high-dose vinegar with cholesterolemic diet induced a significant decrease in ox-LDL compared to hypercholesterolemic diet $(P=.020)$. The difference between low and high-doses vinegar was not significant (Table 5).

\section{Discussion}

Concomitant consumption of cholesterol enriched diet with vinegar modifies the atherogenic effects of cholesterol and significantly prevents the increase of ox-LDL, MDA, LDL-C, ApoB100, TC, glucose and fibrinogen.

Food intake is generally followed with a raised level of triglyceride and glucose as well as increased oxidative

Table 4 Comparison of fibrinogen and C-reactive protein(CRP) values before (baseline) and after (postprandial) experimental diet

\begin{tabular}{llllll}
\hline Biochemical factors & \multicolumn{2}{c}{ Groups } & & \\
\hline & & Cholesterolemic diet & $5 \mathrm{ml}$ Vinegar with \%1 chol & $10 \mathrm{ml}$ Vinegar with \%1 chol & Normal diet \\
$\mathrm{CRP}(\mu \mathrm{g} / \mathrm{ml})$ & baseline & $2.43 \pm 0.35$ & $2.37 \pm 0.26$ & $2.48 \pm 0.32$ & $2.51 \pm 0.12$ \\
& postprandial & $3.72 \pm 0.20$ & $3.42 \pm 0.19$ & $3.46 \pm 0.16$ & $3.02 \pm 0.27^{*}$ \\
fibrinogen $(\mathrm{mg} / \mathrm{dl})$ & baseline & $195.4 \pm 17.2$ & $227.6 \pm 51.9$ & $209.17 \pm 20.3$ & $240.75 \pm 16.8$ \\
& postprandial & $256 \pm 35.3$ & $221.5 \pm 53.3^{*}$ & $228.83 \pm 38.3$ & $257.75 \pm 23.3$ \\
\hline
\end{tabular}

Mean CRP and fibrinogen, $\mu \mathrm{g} / \mathrm{ml} \pm \mathrm{SD}$ and $\mathrm{mg} / \mathrm{dl} \pm \mathrm{SD}$, respectively, in each group $(\mathrm{n}=8$ for each experimental group).* $<0.05$ : Pairwise comparison of differences between baseline and postprandial when compared to cholesterolemic group. 
Table 5 Comparison of oxidative factors values before (baseline) and after (postprandial) experimental diet

\begin{tabular}{llllll}
\hline Biochemical factors & \multicolumn{3}{l}{ Groups } & & \\
\hline & & Cholesterolemic diet & $5 \mathrm{ml}$ Vinegar with \%1 chol & $10 \mathrm{ml}$ Vinegar with \%1 chol & Normal diet \\
MDA (mol/l) & baseline & $1.42 \pm 0.37$ & $1.4 \pm 0.29$ & $1.35 \pm 0.32$ & $1.28 \pm 0.20$ \\
& postprandial & $2.88 \pm 0.71$ & $2.25 \pm 0.46$ & $2.04 \pm 0.40^{*}$ & $1.18 \pm 0.18^{*}$ \\
OXLDL $(\mathrm{ng} / \mathrm{ml})$ & baseline & $32.99 \pm 11.2$ & $30.05 \pm 6.3$ & $33.38 \pm 18.8$ & $24.08 \pm 6.6$ \\
& postprandial & $69.59 \pm 19.4$ & $54.25 \pm 32.0$ & $52.41 \pm 28.2^{*}$ & $34.62 \pm 7.6^{*}$ \\
\hline
\end{tabular}

Mean MDA and OXLDL, $\mathrm{mol} / \mathrm{l} \pm \mathrm{SD}$ and $\mathrm{ng} / \mathrm{ml} \pm \mathrm{SD}$, respectively, in each group $(\mathrm{n}=8$ for each experimental group).* $<0.05$ : Pairwise comparison of differences between baseline and postprandial when compared to cholesterolemic group.

reactions. In postprandial state, cellular structures such as proteins, carbohydrates, nucleic acids and lipids are damaged by oxidative processes [27]. Some recent studies $[1,28,29]$ have suggested that a high fat diet including TG rich lipoproteins plays a role in initiation of atherosclerosis since it can cause an acute modification in endothelial function. This effect begins two hours after food intake and continues for several hours. It is supposed that raised postprandial TG and cholesterol levels are mainly responsible for this effect. Using lowdose vinegar with cholesterolemic diet induced a significant decrease in serum glucose level compared to hypercholesterolemic diet. Results of Johnston CS et al indicated that vinegar and peanut products as complementary foods to reduce postprandial glycemia [16]. The antiglycemic property of vinegar might be due to the inhibitory effect of acetic acid on some enzymes of metabolism carbohydrate such as sucrose, lactase and maltase activities during the posttranslational processing [30]. Delayed gastric emptying might also contribute to antiglycemic effect of vinegar [31].

In case of lipid profile, we found that high-dose vinegar can make a significant acute decrease in TC, LDL-C concentrations and obviously it was much more effective than $5 \mathrm{ml}$ vinegar. According to the results of Fushimi, Sato et al, acetic acid reduced malonyl-CoA in the liver of rats under postprandial condition [32]. Since the activation of AMP-activated protein kinase (AMPK) (inhibitor of fatty acid and sterol synthesis) leads in the reduction of malonyl-CoA content [33], thus consumption of acetic acid can influence lipid synthesis. Daher et al found a decreased plasma level of TG and chylomicrons concomitantly with delayed gastric emptying three hours after ingestion of pineapple and grapefruit in normolipidemic rats [21].

Apolipoproteins such as ApoB are known as significant predictors of development atherosclerosis and even better than lipid profile [34].

Using high-dose vinegar induced a significant decrease in ApoB100 compared to hypercholesterolemic diet. Decrease of ApoB suggests an effect on lipoprotein production, such as a delay in fat reabsorbtion and or a decrease in the secretion of the particles from entrocytes. Studies conducted on the components of vinegar have shown the presence of high amounts of polyphenols, vitamin $C$ and organic acids $[10,11]$. Juhel et al suggested a mechanism by which polyphenols may decrease fat digestion and absorption in gastric. They indicated that lipid emulsification process in gastric and pancreatic lipase activity in gastric and duodenal media is inhibited by cateching-rich polyphenolic $[35,36]$. Polyphenols have also been shown to play a role in the controlling of key intracellular enzymes contributed in the synthesis and secretion of ApoB-containing lipoproteins [37,38]. ApoA, which has a protective role in cardiovascular diseases was increased in vinegar taking groups specially $5 \mathrm{ml}$ vinegar $(P>.05)$. Using high-dose vinegar was significantly better than low dose vinegar in decreasing ApoB100 level $(P<$ .05). The effect of acute red wine polyphenol consumption on postprandial lipaemia in postmenopausal women studied by Naissides $M$ et al and they concluded that dealcoholised red wine (DRW) consumption did not affect on postprandial TG level but, qualitatively, after 6 hours DRW can reduce the exposure of arteries to lipoprotein containing apoB48 [39].

Recently in several studies the association of liver transaminases with some components of metabolic syndrome has been reported. It has been supposed that an increasing SGOT/SGPT ratio can predict coronary atherosclerosis [40]. However, we did not find any significant acute effect of vinegar on serum transaminases.

Nitric oxide (NO) is the most important endothelium derived vasodilator. In our study, nitrite increased in high cholesterol control compared to normal diet. Both low and high-doses vinegar with cholesterolemic diet showed a reduction in nitrite compared with high cholesterol control, however the difference was not significant. Pergola et al investigated the effect of anthocyanin fraction of black berry extract on nitric oxide and found that anthocyanin can suppress NO production through inhibition of expression and activation of inducible nitric oxide synthase (iNOS). In particular, the protein expression was inhibited through the reduction of NF- $\kappa \mathrm{B}$ and/ or mitogen activated protein kinase (MAPK) activation [41]. The same mechanism might be considered for vinegar in lowering $\mathrm{NO}$ metabolites. The acute and chronic effects of drinking alcoholic beverages at dinner on serum nitrate and nitrite (NOx) was studied by 
Sierksma A et al [42]. They indicated that though an acute and transient increase of NOx would be observed following food intake, but the concomitant use of alcoholic beverages would decrease the effect slightly.

No significant difference was found between vinegar taking groups and high cholesterol control in CRP. In high cholesterol group, CRP was increased significantly compared to the normal diet group. Inflammatory process and thrombosis/fibrinolysis system investigated by Tousoulis et al and no significant change of inflammatory factors was shown in any of the studied groups [43]. In study performed by Alexopoulos et al on the acute effect of green tea consumption on endothelial function in normal subjects, they measured CRP at baseline and at $120 \mathrm{~min}$ after consumption green tea and caffeine and results of their studies showed that tea and caffeine had no effect on CRP [44].

We may conclude that vinegar does not affect acutely on CRP but future studies should investigate chronic effects and also consider other markers of inflammation.

We found that low-dose vinegar appeared to be effective in reducing plasma fibrinogen concentration $(P<$ $.05)$. Though reduced fibrinogen level was found in high-dose vinegar comparison to hypercholesterolemic diet but the difference was not significant.

According to the results of Grenett $\mathrm{HE}$ et al polyphenols (catechin and quercetin) may have cardioprotective properties due to alterations of fibrinolytic protein mRNA expression and the resultant increased fibrinolysis of endothelial cells [45].

MDA as a thiobarbituric acid reactive substance is the end-product of lipid preoxidation. Considering the cytotoxicity and genotoxicity of lipid oxidation end products (ALEs) like oxycholesterol, 4-hydroxy-nonenal, and malondialdehyde, consumption of high-fat foods containing ALEs is relatively responsible for atherosclerosis [46,47].

We found that in high-dose vinegar MDA level decreased significantly compared to cholesterol rich diet and this acute effect means that flavonoid contents of vinegar might be effective in reducing lipid peroxidation and enhance the antioxidant enzyme activity [48]. Reduction in atherosclerosis by antioxidants has been related with a decrease in reduction MDA $[49,50]$. Several studies indicated that flavonoids can prevent lipid peroxidation in microsomes and liposomes. The antioxidant potency of flavonoids in these studies depends on the arrangement of hydroxyl groups on the benzene ring [51-54].

Gorelik $S$ et al investigated effect of red wine on postprandial MDA. The results revealed a relatively rapid accumulation of MDA in plasma, with a maximum level achieved $3 \mathrm{~h}$ after the meal. They showed that red wine prevent absorption of the lipotoxin MDA [55]. Further studies should be focused on antioxidant potential of vinegar and the mechanisms.
The ways postprandial hyperlipemia might induce its atherosclerotic effects have been studied by Natella et al [55]. As a probable mechanism, increased postprandial level of plasma lipid hydroperoxides (LPO) and the resultant increased susceptibility of LDL to oxidation were suggested. This phenomenon is mediated by LPO-induced effects on oxidant/antioxidant balance [56].

As expected, using high-dose vinegar with cholesterolemic diet induced a significant decrease in ox-LDL compared to hypercholesterolemic diet. The mechanism by which flavonoids inhibit LDL is not totally known, but it is supposed that they decrease free radical formation, protect LDL- $\alpha$-tocopherol or regenerate oxidized LDL- $\alpha$-tocopherol, and/or separate metal ions which contribute in oxidation reactions $[57,58]$.

Studies indicated that the phenolic compound contents of red wine [59] and walnuts [60] can lower oxidation LDL after acute consumptions of these foods. According to the results of Natella et al using grape seed proanthocyanidins with meal can lower the postprandial oxidative stress through decreasing oxidants concentration and increasing the level of serum antioxidants. These effects can eliminate the oxidative modification of LDL [55].

Kondo et al demonstrated that 2 hours after consumption of 35 grams of defatted cocoa enhanced the resistance to oxidative modification of LDL [61]. Several studies suggest that postprandial lipemia increases risk of atherogenesis, thus assessment and treatment of atherosclerosis should include parameters associated to postprandial lipemia. Diets high in fat is contributory risk factors, whereas consumption of polyphenol-rich fruits and vegetables during the meal seems to reduce these risk factors. The results of this study show that vinegar consumption with hypercholesterolemic diet decrease destructive effects of a cholesterol rich diet. Different doses of vinegar show different effects on biochemical factors. Low-dose vinegar affect on fibrinogen and glucose and high-dose vinegar has significant effect on MDA, ox-LDL, TC, ApoB, and LDL-C. Therefore it seems that higher dose affect on lipoproteins, apolipoproteins and oxidation. Further effort is needed to improve the reliability of these results and to shed light on underlying mechanisms. Also future researches must focus on chronic effects of vinegar intake. Although the present data do not allow the conclusion that vinegar intake has an acute protective value for atherosclerosis, it seems reasonable to conclude that the results can probably show the favorable acute effects of vinegar on some of the biochemical risk factors of atherosclerosis. Regarding the availability and affordability of vinegar, these findings indicate the potential for vinegar to be considered in prevention of 
some of the risk factors of atherosclerosis. Future studies must focus on determining similar effects of vinegar on human.

\section{Acknowledgements}

This study was supported by Islamic Azad University, Tehran, Iran, (Grant \# 584151). The authors thankfully acknowledge Isfahan cardiovascular research center and Isfahan University of Medical Sciences.

\section{Author details}

'Department of Biology, Science and Research Branch, Islamic Azad University, Tehran, Iran. ${ }^{2}$ Isfahan Cardiovascular Research Center, Applied Physiology Research Center, Isfahan University of Medical Sciences, Isfahan, Iran. ${ }^{3}$ Department of Physiology, Faculty of Medicine, Isfahan University of Medical sciences, Isfahan.

\section{Authors' contributions}

MKH participated in the sequence alignment and drafted the manuscript, NE carried out the laboratory tests. AE participated in the sequence alignment. MS participated in the design of the study and performed the statistical analysis. AHR conceived the study, and participated in its design and coordination. All authors read and approved the final manuscript.

\section{Competing interests}

The authors declare that they have no competing interests.

Received: 28 October 2009

Accepted: 28 January 2010 Published: 28 January 2010

\section{References}

1. Vogel RA, Corretti MC, Plotnick GD: Effect of a single high-fat meal on endothelial function in healthy subjects. Am J Cardiol 1997, 79:350-354.

2. Creager MA, Cooke JP, Mendelsohn ME: Impaired vasodilation of forearm resistance vessels in hypercholesterolemic humans. J Clin Invest 1990, 86:224-228.

3. Ceriello A, Taboga C, Tonutti L: Evidence for an Independent and Cumulative Effect of Postprandial ypertriglyceridemia and Hyperglycemia on Endothelial Dysfunction and Oxidative Stress Generation: Effects of Short- and Long-Term Simvastatin Treatment. Circulation 2002, 106:1211-1218.

4. Nitenberg A, Cosson E, Pham I: Postprandial endothelial dysfunction: role of glucose, lipids and insulin. Diabetes Metab 2006, 32:S28-33.

5. Baldwin AS Jr: The NF-kappa B and I kappa B proteins: new discoveries and insights. Annu Rev Immunol 1996, 14:649-683.

6. Jagla A, Schrezenmeir J: Postprandial triglycerides and endothelial function. Exp Clin Endocrinol Diabetes 2001, 109:S533-547.

7. Pearson DA, Tan CH, German JB: Apple juice inhibits human low density lipoprotein oxidation. Life Sci 1999, 64:1913-1920.

8. Shanmuganayagam $D$, Warner $T$, Folts J: Effect of grape juice flavonoids on experimental atherosclerosis. FASEB J 2000, 14:A455.

9. Stein JH, Keevil JG, Wiebe DA: Purple grape juice improves endothelial function and reduces the susceptibility of $L D L$ cholesterol to oxidation in patients with coronary artery disease. Circulation 1999, 100:1050-1055.

10. Shahidi F, McDonald J, Chandrasekara A, Zhong Y: Phytochemicals of foods, beverages and fruit vinegars:chemistry and health effects. Asia Pac J Clin Nutr 2008, 17(Suppl 1):380-382.

11. Johnston CS, Gaas CA: Vinegar: Medicinal uses and antiglycemic effect. Med Gen Med 2006, 8:61.

12. Fushimi T, Tayama K, Fukaya M: acid feeding enhances glycogen repletion in liver and skeletal muscle of rats. J Nutr 2001, 131:Acetic1973-1977.

13. Kondo S, Tayama K, Tsukamoto Y: Antihypertensive effects of acetic acid and vinegar on spontaneously hypertensive rats. Biosci Biotechnol Biochem 2001, 65:2690-2694.

14. Kishi M, Fukaya M, Tsukamoto Y: Enhancing effect of dietary vinegar on the intestinal absorption of calcium in ovariectomized rats. Biosci Biotechnol Biochem 1999, 63:905-910.

15. Fushimi T, Suruga K, Oshima Y: Dietary acetic acid reduces serum cholesterol and triacylglycerols in rats fed a cholesterol-rich diet. $\mathrm{Br} J$ Nutr 2006, 95:916-924.
16. Johnston CS, Buller AJ: Vinegar and peanut products as complementary foods to reduce postprandial glycemia. J Am Diet Assoc 2005, 105:1939-1942.

17. Ostman $E$, Granfeldt $Y$, Persson L: Vinegar supplementation lowers glucose and insulin responses and increases satiety after a bread meal in healthy subjects. Eur Clin Nutr 2001, 59:983-988.

18. Hromatka O, Ebner H: Vinegar by Submerged Oxidative Fermentation. Ind Eng Chem 1959, 10:1279-1280.

19. Asgary S, Jafari Dinani N, Madani H: Effect of glycyrrhiza glabra extracts on aorta wall atherosclerotic lesion in hypercholesterolemic rabbits. Pak J Nutr 2007, 6:313-317.

20. Decorde K, Teissedre PL, Auqer C: Phenolics from purple grape, apple, purple grape juice, and apple juice prevent early atherosclerosis induced by an atherogenic diet in hamsters. Mol Nutr Food Res 2008, 2:400-407.

21. Daher CF, Abou-Khalil J, Baroody GM: Effect of acute and chronic grapefruit, orange and pineapple juice intake on blood lipid profile in normolipidemic rat. Med Sci Monit 2005, 11:465-472.

22. Kostner K, Hornykewycz S, Yang P: Is oxidative steress causally linked to unstable angine apectoris? A study in 100 CAD patients and matched control. Cardiovasc Res 1997, 36:330-336.

23. Mccormick DB, Greene HL: Vitamins. Tietz Text Book of Clinical Chemistry Philadelphia: W. B. SaundersCarl A, Britis Edward R, Ashwood 1994, 2:1313-1314

24. Kumar S, Kumar D, Rakash O: Evaluation of antioxidant potential, phenolic and flavonoid contents of hibiscus tiliaceus flowers. EJAFche 2008, 7:2863-2871.

25. Francis FJ: In anthocyanins as food colors. New york:Academic press 1982, 181-207.

26. Lenghor N, Jakmunee J, Vilen M, Sara R, Christian GD, Grudpan K: Sequential injection redox or acid-base titration for determination of ascorbic acid or acetic acid. Talanta 2002, 6:1139-44.

27. Kay CD, Holub BJ: The postprandial effects of dietary antioxidants in humans. Curr Atheroscler Rep 2003, 5:452-458.

28. Slyper AH: A fresh look at the atherogenic remnant hypothesis. Lancet 1992, 340:289-291.

29. Ross R: The pathogenesis of atherosclerosis: a perspective for the 1990's. Nature 1993, 362:801-809.

30. Ogawa N, Satsu H, Watanabe H: Acetic acid suppresses the increase in disamlharidase activity that omlurs during culture of caco-2 cells. J Nutr 2000, 130:507-513.

31. Liljeberg H, Bjorck I: Delayed gastric emptying rate may explain improved glycaemia in healthy subjects to a starchy meal with added vinegar. Eur J Clin Nutr 1998, 52:368-371.

32. Fushimi $T$, Sato $Y$ : Effect of acetic acid feeding on the circadian changes in glycogen and metabolites of glucose and lipid in liver and skeletal muscle of rats. Br J Nutr 2005, 94:714-719.

33. Saha AK, Ruderman NB: Malonyl-CoA and AMP-activated proteinkinase: an expanding partnership. Mol Cell Biochem 2003, 253:65-70.

34. Chan DC, Watts GF: Apolipoproteins as markers and managers of coronary risk. QJM 2006, 99:277-287.

35. Juhel C, Armand M, Pafumi Y, Rosier C: Green tea extract (AR25) inhibits lipolysis of triglycerides in gastric and duodenal medium in vitro. J Nutr Biochem 2000, 11:45-51.

36. Teissedre $\mathrm{P}$, Landrault $\mathrm{N}$ : Wine phenolics: contribution to dietary intake and bioavailability. Food Res Int 2000, 33:461-467.

37. Wilcox $L$, Borradaile NM, de Dreu LE: Secretion of hepatocyte apoB is inhibited by the flavonoids, naringenin and hes peretin, via reduced activity and expression of ACAT2 and MTP. J Lipid Res 2001, 42:725-734.

38. Kim HK, Jeong TS, Lee MK: Lipid-lowering efficacy of hesperetin metabolites in high-cholesterol fed rats. Clin Chim Acta 2003, 327:129-137.

39. Naissides M, Mamo JC, James AP: The effect of acute red wine polyphenol consumption on postprandial lipaemia in postmenopausal women. Atherosclerosis 2004, 177:401-408.

40. Adibi P, Sadeghi M, Mahsa M: Prediction of coronary atherosclerotic disease with liver transaminase level. Liver Int 2007, 27:895-900.

41. Pergola C, Rossi A, Dugo P: Inhibition of nitric oxide biosynthesis by anthocyanin fraction of blackberry extract. Nitric Oxide 2006, 15:30-39.

42. Sierksma A, Gaag van der MS, Grobbee DE: Acute and chronic effects of dinner with alcoholic beverages on nitric oxide metabolites in healthy men. Clin Exp Pharmacol Physiol 2003, 30:504-506. 
43. Tousoulis D, Ntarladimas I, Antoniades C: Acute effects of different alcoholic beverages on vascular endothelium, inflammatory markers and thrombosis fibrinolysis system. Clin Nutr 2008, 27:594-600.

44. Alexopoulos N, Vlachopoulos C, Aznaouridis K, Baou K, Vasiliadou C, Pietri P, Xaplanteris P, Stefanadi E, Stefanadis C: The acute effect of green tea consumption on endothelial function in healthy individuals. Eur $\mathrm{J}$ Cardiovas Prev Rehabil 2008, 15:300-305.

45. Grenett HE, Abou-Agag LA, Parks DA: Ethanol and polyphenols (CAT, QUER) increase expression of fibrinolytic protein mRNAs in vivo in rat aortic endothelium. Biol Res 2004, 37:342.

46. Ursini F, Zamburlini A, Cazzolato G: Postprandial plasma lipid hydroperoxides: a possible link between diet and atherosclerosis. Free Radic Biol Med 1998, 25:250-252.

47. Cohn JS: Oxidized fat in the diet, postprandial lipaemia and cardiovascular disease. Opin Lipidol 2002, 13:19-24.

48. Zou Y, Lu Y, Wei D: Hypercholesterolemic effects of a flavonoid-rich exteract of hypericum perforatum L. in rats fed a cholesterol-rich diet. J Agric Food Chem 2005, 53:2462-2466.

49. Prasad K, Kalra J: Oxygen free radicals and hypercholesterolemic atherosclerosis: effect of vitamin E. Am Heart J 1993, 25:958-973

50. Prasad K, Kalra J, Lee P: Oxygen free radicals as a mechanism of hypercholesterolemic atherosclerosis: effects of probucol. Int J Angiol 1994, 3:100-112.

51. Cao G, Sofic E, Prior R: Antioxidant and prooxidant behavior of flavonoids: structure-activity relationships. Free Radic Biol Med 1997, 22:749-760.

52. Van Acker SA, Berg van den DJ, Tromp MN: Structural aspects of antioxidant activity of flavonoids. Free Radic Biol Med 1996, 20:331-342.

53. Arora A, Nair MG, Strasburg GM: Antioxidant activities of isoflavones and their biological metabolites in a liposomal system. Arch Biochem Biophys 1998, 356:133-141.

54. Arora A, Nair MG, Strasburg GM: Structure-activity relationships for antioxidant activities of a series of flavonoids in a liposomal system. Free Radic Biol Med 1998, 24:1355-1363.

55. Gorelik SG, Ligumsky M, Kohen R, Kanner J: A novel functions of red wine polyphenols in humans: prevention of absorption of cytotoxic lipid peroxidation products. FASEB 2008, 22:41-46.

56. Natella F, Belelli F, Gentili V: Grape seed proanthocyanidins prevent plasma postprandial oxidative stress in humans. J Agric Food Chem 2002, 50:7720-7725.

57. Cook NC, Samman S: Flavonoids-Chemistry, metabolism, cardioprotective effects, and dietary sources. J Nutr Biochem 1996, 7:66-76.

58. Yan $L$, Droy-Lefaix MT, Packer L: Ginkgobiloba extract (EGb 761) protects human low density lipoproteins against oxidative modification mediated by copper. Biochem Biophys Res Comm 1995, 212:360-366.

59. Covas Ml, Konstantinidou V, Mysytaki E, Fitó M, Weinbrenner T, De La Torre R, Farré-Albadalejo M, Lamuela-Raventós R: Postprandial effects of wine consumption on lipids and oxidative stess biomarkers. Drugs Exp Clin Res 2003, 29:217-223.

60. Cortés B, Núñez I, Cofán M: Acute effects of high-fat meals enriched with walnuts or olive oil on postprandial endothelial function. JACC 2006, 48:1666-1671.

61. Kondo K, Hirano R, Matsumoto A: Inhibition of LDL oxidation by cocoa. Lancet 1996, 348:1514.

doi:10.1186/1476-511X-9-10

Cite this article as: Setorki et al:: Acute effects of vinegar intake on some biochemical risk factors of atherosclerosis in hypercholesterolemic rabbits. Lipids in Health and Disease 2010 9:10.

\section{Submit your next manuscript to BioMed Central and take full advantage of:}

- Convenient online submission

- Thorough peer review

- No space constraints or color figure charges

- Immediate publication on acceptance

- Inclusion in PubMed, CAS, Scopus and Google Scholar

- Research which is freely available for redistribution

Submit your manuscript at www.biomedcentral.com/submit
Biomed Central 